\title{
CONSIDERACIONES SOBRE LA PỌBLACIÓN, EL DESARROLLO Y LA POLITICA DE POBLACIÓN EN MÉXICO
}

\author{
RAÚl Benítez ZeNTENo * \\ Universidad Nacional Autónoma de México
}

\section{INTRODUCCIÓN}

EN EL CURSo de la historia generalmente se ha supuesto que el crecimiento de la población y una población más numerosa corresponden a mejores condiciones de vida, aun después de los planteamientos de Malthus y con la excepción de visiones utópicas como las de Platón, Campanella, Moro o Fourier. Lo anterior es particularmente cierto cuando se trata de los planteamientos políticos que se derivan del ejercicio del poder. Sólo en los últimos treinta años ha sido posible llegar a situaciones nacionales - como la de China, Corea del Norte, la de algunos países socialistas, en parte en los países nórdicos, Japón y unos pocos másen donde la población y particularmente el control de su crecimiento se considera como un factor estructural de tal importancia que no debe abandonarse a su propia dinámica; ésta resulta fundamentalmente del proceso de cambio global y sobre ella pueden orientarse políticas y acciones concretas.

En situaciones de subdesarrollo y dependencia neocolonial en las que se han implantado programas nacionales de control del crecimiento demográfico como en Corea del Sur, Indonesia, Filipinas, Tailandia, India, Paquistán, Ceilán, Turquía, Irán, Honduras, Nicaragua Trinidad y Tobago, etc., la fuerte dinámica de la población se considera como un obstáculo al desarrollo, y los programas de control del crecimiento demográfico se relacionan generalmente con los de salud, de prevención del aborto, de educación, y otros; las consideraciones sobre la población se dan aisladas del conjunto de decisiones y no logran un carácter generalizado en su aplicación, dado que no existen - salvo excepciones- programas de desarrollo nacional más o menos integrados.

En otros casos se considera necesaria una población más numerosa, particularmente por la existencia de zonas con muy baja densidad de población; se busca con ello la explotación de los recursos no aprovechados. Por otra parte, subsiste la idea de que la "pujanza" de un país está en relación directa con una población numerosa y creciente. Tal es el caso de países como Camerún, la República de Mali, Birmania, Argentina y algunas regiones de Brasil.

En la mayoría de los países atrasados y como resultado de planteamientos surgidos en los países imperialistas, el interés por las tesis malthusianas es cada vez mayor, consecuente con la expansión demográfica

* Agradezco a Mónica Mansour la lectura y corrección expresiva del trabajo. 
de los últimos treinta años y las limitaciones estructurales de la dependencia colonial. Tal es el caso de la mayoría de los países latinoamericanos.

En los países capitalistas avanzados se realizan esfuerzos considerables con el fin de formular políticas demográficas para el futuro, a partir del análisis del impacto de la población en los distintos factores: económico, ecológico, social, político, etc. Se tiende, en general (salvo en el caso de los críticos del propio sistema capitalista), a evadir los planteamientos en los que la dinámica de la población es el resultado del propio sistema, que sobrevive precisamente en función de sus desequilibrios internos, sus excedentes demográficos, su modo de producción y explotación interna y externa, la manera en que se mantiene el dominio neocapitalista de las superpotencias, etc.

\section{El CONTEXTO HISTÓRICO LATINOAMERICANO}

En el gran contexto del subdesarrollo, los países latinoamericanos tienen orígenes históricos menos diferenciados que los países africanos, los asiáticos o los del Cercano Oriente. En cuanto a niveles de desarrollo relativo global, América Latina tiene en la actualidad una posición superior y menos diferenciada que el resto de los países que integran las regiones mencionadas. Sin embargo, esta mayor homogeneidad encubre diferencias importantes, que se acentúan al considerar los desequilibrios internos, regionales o nacionales.

En la etapa colonial las diferencias prehispánicas desaparecen parcialmente, dado el proceso de explotación con una orientación más bien continental que regional, la cual guía también el surgimiento a la vida independiente; así se constituye una historia más o menos común. E1 propio proceso de explotación colonial, junto con las situaciones internas previas o determinadas por la existencia de recursos diferentes y formas particulares de dominio interno, traen como consecuencia una mayor diferenciación: ésta toma diversas rutas en la etapa independiente y tiende a convergir de nueva cuenta cuando la hegemonía de los Estados Unidos sobre América Latina impone patrones de desarrollo industrial. Así, las diferencias resultan de la manera en que cada nación ha incorporado su economía a la internacional en los distintos momentos, desde la etapa dependiente colonial hasta la dependiente capitalista actual. Esos procesos van desde el enclave agrícola-minero que prevaleció hasta principios del siglo xIx hasta el sistema internacional actual; éste se caracteriza por la integración del capital a nivel internacional, que presenta intercambios cada vez más protegidos por parte de los países dominantes y una incorporación creciente - dentro de la estructura de corporación multinacional- del capital nativo aliado con el internacional.

Las diferencias actuales entre los países son considerables en lo económico, lo social y lo político y consecuentemente en la dinámica, la estructura y la distribución de la población.

\section{El CONTEXTo HistóRICO MEXICANo}

Los requerimientos de una población numerosa se manifiestan desde antes de la Colonia. Las sociedades prehispánicas, desde sus etapas for- 
mativas basan su subsistencia en modos de producción esencialmente extensivos, tanto agrícolas como de recolección y caza; desarrollan después centros ceremoniales asociados a la incorporación del riego y al empleo de metales, y terminan con organizaciones teocrático-militares que tienen justificaciones cósmico-religiosas y que requieren una mano de obra muy numerosa. Sus objetivos de culto y perduración de la propia especie - mediante el mantenimiento de los dioses en permanente retroalimentación- y el carácter expansivo de la dominación teocráticomilitar requieren una población mayor, particularmente en el desarrollo de su etapa metropolitana.

La Conquista, el inicio de la Colonia y la gran depresión demográfica del siglo XVI - expresiones del nuevo proceso de dominación- llevaron a la necesidad de arraigar la población a la tierra, como mano de obra cautiva; por la necesidad de más población, este sistema en general operó en siglos siguientes.

El período colonial constituyó una etapa de acumulación mercantilista. Para la metrópoli significó un proceso acelerado de acumulación de capital; para la colonia significó desacumulación relativa y orientar el modo de producción en términos de la construcción de canales de explotación mediante enclaves agrícola-mineros que requerían una población numerosa. Esto fue así por el carácter extensivo de la producción agrícola y pecuaria, por el carácter masivo de la explotación minera y por el carácter extensivo del intercambio, dominado por las orientaciones de la metrópoli y determinado por sus propias necesidades.

Esta orientación colonial termina con la independencia, y los modos de producción se dirigen hacia nuevas formas de dependencia que requieren a su vez bastante mano de obra, como son los imperios industriales y financieros. No obstante, sobreviven hasta el presente organizaciones productivas semejantes a las empleadas en la Colonia. Se llega así a la etapa de intervenciones y de pérdida de la mitad de nuestro territorio, de reforma y liberalismo y de penetración de capitales, particularmente durante el porfiriato. En esta etapa surge también el capital financiero criollo íntimamente ligado al del exterior, como consecuencia de la explotación agrícola extensiva y el mantenimiento de la actividad minera, aunque a niveles inferiores que en el pasado. Se crea también una cierta infraestructura económica en los transportes y servicios necesarios para movilizar la producción agrícola, la minera y la incipiente producción industrial.

En todos estos momentos se hace necesario mantener una elevada fecundidad, que debía exceder la elevada mortalidad y permitir un crecimiento demográfico positivo. Esto se manifiesta en el desarrollo de normas religiosas, leyes, costumbres, patrones matrimoniales y estructuras familiares, etc., para lograr un número suficiente de nacimientos que significan una oferta amplia de mano de obra. Esta población se constituye en factor estratégico del movimiento revolucionario de 1910, que se acumuló particularmente después de la "compactación" de la propiedad agraria y el sistema de peonaje extenso en la tierra propia, realizadas a partir de la acción de las compañías deslindadoras.

A partir de 1920 se dan las bases del nuevo Estado: primero, la satisfacción de las demandas agrarias y la institucionalización del posterior desarrollo, planteado por Calles y consolidado por Lázaro Cárdenas; 
segundo, la nueva formación de capital a partir de las transformaciones sociales inherentes a la Revolución.

\section{LA FORMACIÓN DE LA REALIDAD DE 1970}

En los años treinta y especialmente después de 1940 se inicia una nueva etapa en la dinámica de la población, al comenzar el descenso de la mortalidad, como resultado de las transformaciones sociales iniciadas un poco antes y de la aplicación de los avances en prevención y curación de enfermedades. En el decenio de 1930 a 1939 se intensifica el proceso migratorio del campo a la ciudad, en parte como resultado de la contracción causada por la crisis mundial; de 1932 a 1940 se dio un lento crecimiento de la producción agrícola de sólo $2 \%$ al año. El sector manufacturero creció considerablemente ocupando parte de la población desplazada del sector primario. La crisis del 29 trajo consigo, además, el retorno al país de cerca de medio millón de trabajadores -expulsados de los Estados Unidos-, predominantemente agrícolas que aumentaron la oferta de mano de obra; esto representó nuevamente una presión sobre el mercado de trabajo.

Durante los años cuarenta la acción interna y la situación de posguerra modifican los patrones de producción y de intercambio: aumenta considerablemente la producción agrícola, tanto para consumo interno como para exportación, y continúa creciendo el sector manufacturero. Lo anterior, junto con la incorporación de insecticidas, antibióticos, nueva quimioterapia, así como la ayuda internacional en salud y desde luego las bases institucionales que permitieron una cierta extensión de los servicios, traen consigo una aceleración considerable del crecimiento de la población al disminuir la mortalidad ahora a un ritmo más acelerado y mantenerse constante el nivel de fecundidad. La mayor migración a los centros urbanos y la presencia de una mano de obra dispuesta a incorporarse a la industria con salarios bajos, así como el desarrollo paralelo de la élite obrera coadyuvan a la nueva pauta del desarrollo que deja atrás la posición nacionalista representada por Cárdenas.

El control político de los diversos sectores constituye un factor de peso en la nueva concepción capitalista y aumenta la afluencia de inversiones extranjeras relacionada con la política proteccionista. La nueva industria surge ahora dependiente de la tendencia mundial, con énfasis en cambios tecnológicos más dinámicos. Para los años sesenta el desarrollo industrial supera el crecimiento económico general, en particular en el sector manufacturero, a donde se ha dirigido preferentemente la inversión directa del exterior, que se expande a las industrias de mayor dinamismo. A partir de 1960 el capital extranjero adopta nuevas modalidades como la de adquisición de industrias establecidas y su integración cada vez mayor al sistema de operación multinacional.

Los movimientos de población desde los años cuarenta hasta la fecha mantienen su tendencia más o menos uniforme de mayor concentración, a medida que el crecimiento demográfico se eleva. El desequilibrio entre oferta y demanda de trabajo, junto con la expansión demográfica, mantuvieron los bajos salarios reales y contribuyeron a mantener la corriente migratoria del campo a la ciudad; no por esto disminuyeron los niveles 
de desocupación y subocupación rural en los que se apoya, como punto de partida, gran parte del crecimiento urbano.

Así, llegamos en 1970 a un desempleo abierto del $7.5 \%$, constituido en su mayoria por "viejos buscadores de trabajo"; al mismo tiempo había un $5.3 \%$ de la población económicamente activa que buscaba mejor trabajo; un 19\% de la PEA ocupada menos de diez meses al año; por otra parte, del $89 \%$ de la población que declaró ingresos en el censo de población, un $72 \%$ manifestó un ingreso menor a los mil pesos mensuales; asimismo, la población campesina ocupada sólo temporalmente era de cuatro millones. Si a éstos agregamos los desocupados que no buscan empleo porque sencillamente no piensan encontrarlo, tendremos una idea aproximada de nuestros grandes desequilibrios internos, nuestra miseria y la explotación. Se debe considerar, además, una población de más de cuatro millones de mexicanos residentes en los Estados Unidos, lo que hace más evidente la incapacidad del sistema para incorporar toda la oferta de mano de obra.

En los diversos momentos analizados, la población y su dinámica es, por una parte, resultado del proceso de cambio, y por otra un factor de presión importante sobre el propio cambio: la presión demográfica para el cambio justicialista en el campo, expresado en la Reforma Agraria, trajo consigo en una primera etapa la expansión considerable de la producción agrícola basada en el mayor uso de mano de obra y después, conjuntamente con grandes inversiones básicas, creó excedentes que participaron en el aumento de la inversión. Además, la consolidación del proceso industrial, sin llegar a ser avanzado, en gran parte fue posible por la existencia de mano de obra barata; y la mayor concentración de la población llevó a la creación de servicios en todos los órdenes.

Los patrones adoptados de desarrollo capitalista sin duda han agudizado los desequilibrios existentes. Esto lleva, en el decenio de los setentas, a una situación en la que el crecimiento tan acelerado de la población continúa, por una parte, presionando para el logro de una mayor participación de la población en el beneficio de su trabajo y, por otra, se constituye en barrera para el propio cambio: ambos casos son expresión de las contradicciones del sistema.

Los desequilibrios internos se dan en todos los niveles y la tendencia a situaciones aún más agudas sin duda resulta del patrón de desarrollo de producción capitalista. En la agricultura se advierte en la continua tendencia a la concentración de la tierra, tanto en la propiedad privada como en el ejido, en el uso intensivo de capital y tecnología, con la consecuente menor participación de mano de obra (la nueva mano de obra incorporada a la agricultura de 1950 a 1970 sólo significó el $7.1 \%$ respecto al total de nueva mano de obra y lo más probable es que en este decenio disminuya en cifras absolutas). En la industria, aparece en el desplazamiento de las plantas pequeñas y medianas, en la participación más intensiva del capital y en el estancamiento de su capacidad relativa de absorción de mano de obra. Además, se da una gran concentración de la población en actividades terciarias, con bajos niveles de ingreso (de 1950 a 1970 los servicios absorbieron el $55 \%$ de la nueva mano de obra). Toda esta problemática se enfrenta al objetivo básico del sistema capitalista: la creación de excedente económico, por la vía de la dependencia del 
salario y que en situaciones de subdesarrollo implica también acumulación hegemónica.

\section{POLÍtICA DE POBLACIÓN}

Una de las características de nuestro subdesarrollo es que la presión que impone el crecimiento demográfico transforma las posiciones políticas con respecto a la inclusión de la población como variable estructural básica del cambio.

Los estudios demográficos apenas han permitido conocer la evolución, los niveles y la estructura de las variables demográficas en sí mismas, y sólo se ha podido profundizar en algunas de las relaciones entre cambio demográfico y desarrollo; nada se ha hecho a nivel regional, y hay pocos estudios sobre las relaciones entre población y modos de producción; nada sobre población y clases sociales, etc. Sin duda esta área de conocimiento constituye un sector de interés nacional para su estudio, la orientación de políticas y la acción.

El presidente Luis Echeverría, en la Tercera Reunión de las Naciones Unidas sobre Comercio y Desarrollo realizada en Santiago de Chile en 1972, expuso la conveniencia de un crecimiento demográfico más lento, y así abandonó la tradicional posición oficial de carácter poblacionista. A partir de este momento, lo más seguro es que se amplíe considerablemente la anticoncepción -que adopta los nombres de planificación familiar, paternidad responsable, uso de la decisión individual sobre el número de hijos, etc.- que tiende a reducir el crecimiento de la población.

Con ello, se intenta disminuir la presión demográfica sobre el mercado de trabajo, el sistema educativo, los servicios urbanos, las necesidades de vivienda, etc.; se piensa que es posible en un corto plazo abatir los niveles de fecundidad, y que por esta vía los problemas actuales van a solucionarse en un plazo corto o mediano. Pero me temo que ya es demasiado tarde. A estos planteamientos se les denomina en general "neomalthusianos". Es decir, que se le da al crecimiento demográfico una importancia por encima de la propia estructura social de la cual depende y se le asignan poderes de que no dispone, ni siquiera cuando es muy lento, como sucede en España, Argentina, Uruguay, Chile, Gambia, Liberia, Jamaica, etc.

Los patrones reproductivos elevados son más bien el resultado de la manera en que históricamente se han construido patrones sociales, religiosos, legales, etc., dirigidos hacia la formación de una familia grande. Su transformación depende del cambio de estos patrones y no de una acción externa, como ocurrió al disminuir la mortalidad: todo el mundo está de acuerdo en que hay que vivir más años y que tiene que morir menos gente.

Transformar los patrones reproductivos será sólo consecuencia de transformaciones profundas, que por ahora no queremos o no podemos lograr. En la reproducción intervienen desde los patrones sociales, que designan una cierta edad como más conveniente para el matrimonio, hasta la frecuencia del coito, la capacidad biológica de fertilidad, la posibilidad de educación y de ocupación de los hijos, una vez que se ha observado a la sociedad y entendido su dinámica en lo que se refiere a la 
propia familia. Estos factores funcionan en términos de control estructural - determinado por las orientaciones que resultan de las necesidades de las clases que detentan el poder económico y político-, y han quedado plasmados en la Constitución, en la Iglesia y en los requerimientos del sistema productivo. Es a partir de estos requerimientos que se pueden plantear transformaciones en la población, en sus patrones reproductivos, en su mortalidad, su crecimiento, distribución, etc.

Lo anterior no quiere decir, como generalmente se entiende, que no sea importante el control de la población mediante la anticoncepción: constituye un logro social y es preferible que en vez de abortar se usen anticonceptivos. Lo malthusiano consiste en asignar al control del crecimiento demográfico un papel del que carece; en una situación histórica concreta, es una forma de mantener un sistema a todas luces injusto, en donde sólo unos cuantos se benefician del producto del trabajo de la sociedad en su conjunto, y donde la posibilidad de independencia económica y política en un nivel internacional se encuentra limitada.

Cuando se habla del sistema productivo no puede dejarse de hablar del sistema de poder y dominación. En lo económico, el país se encuentra en tal situación que se hace necesario combatir por todos los medios sus desequilibrios, lo que implica, sin duda, transformaciones sustanciales de la práctica política y consecuentemente de la participación de la población. 